\title{
The Relationship Between Mine Pressure and Gas Emission in Dayang
}

\section{Mine}

\author{
Jun $\mathrm{He}^{1,2 \mathrm{a}}$ \\ 1.State Key Laboratory of Gas Disaster Monitoring and Emergency Technology, Chongqing, 400037, \\ China;
}

2.Chongqing Research Institute of China Coal Technology Group, Chongqing, 400037, China

ahjun987@126.com

\begin{abstract}
Key words: Fully mechanized caving mining, Gas emission, Strata behaviors, Mining technology
\end{abstract}

Abstract: According to the practical condition of 3401 fully mechanized caving face in Dayang coal mine, the relationship between strata behaviors, mining technology and stope gas emission are analyzed through real-time monitoring of the support working resistance, advance abutment pressure and gas concentration of working face. It shows that the change of working face abutment pressure has an obvious effect on the regularity of coal face gas emission. The crest value of gas emission falls behind periodic weighting, the lagging time is about one day. Other factors, like coal production processes, daily coal output and advance speed also have close relationships with gas emission.

\section{Introduction}

Fully mechanized caving mining is an important technology for mining thick coal seam ${ }^{[1,2]}$. It brings huge economic benefit for Daiyang coal mine. But gas over limit on mining face upper corner has become the biggest restricting factors for safe mining in the Daiyang coal mine because the thickness of coal seam is large in the mine and lots of coals left behind in goaf. Though it is low gas mine, but the phenomenon that gas concentration exceeds normal value in mining face upper corner is very frequent. It influences normal mining progress. The characteristic of gas gush is different from general fully mechanized coal face. Taking 3401 mining face as engineering background, the paper researches on a relationship among rock pressure, mining technology and gas emission quantity of fully mechanized sublevel caving face. It gets the regularity and characteristics of gas migration. It can provide technical guarantee for realizing safety and efficient production in the fully mechanized sublevel caving face of low-gas coal mine.

\section{Engineering situation}

The ground level of 3401 mining face is from +972 meters to +1140 meters. The seam floor level is from +670 meters to +1105 meters. The face length on the strike are 1400 meters. The face length along the incline are 160 meters. The dip angel is from $3^{\circ}$ to $12^{\circ}$. Fully mechanized caving mining on the strike is used in the mine, and fully caving coal mining method is used to processing goaf. The average mining height are $4.93 \mathrm{~m}$, caving ratio is $1: 0.9$, and cutting depth is $0.6 \mathrm{~m}$. The coal seam contains 2 3 layers dirt band with the development of two collapse columns and two normal faults in the mining face. The proctor hardness coefficient for coal is three. The coal density is $1.44 \mathrm{t} / \mathrm{m}^{3}$. The mining face doesn't have danger of coal-dust explosion, and it doesn't have spontaneous combustion tendency. The joints and factures develop a lot in the face. The table 1 shows lithology of the coal seam roof and floor. By the analysis of field test and laboratory 
experiments, the basic parameters of the seam gas is showed in the table 2 .

Tab. 1 Roof and floor lithology of 3401 working face

\begin{tabular}{|c|c|c|c|}
\hline Classification & Rock & $\begin{array}{c}\text { Average } \\
\text { thickness(m) }\end{array}$ & Rock characteristics \\
\hline Main roof & Grey middle sandstone & 8.8 & $\begin{array}{l}\text { licon-calcareous cementation, contain locally large amounts of } \\
\text { uscovite, sometimes contains carbonaceous belt }\end{array}$ \\
\hline $\begin{array}{l}\text { Immediate } \\
\text { roof }\end{array}$ & Grey-black mudstone & 4.3 & Contain locally grit siltstone, contains thin coal seam in upper part \\
\hline False roof & Grey-black mudstone & $0 \sim 0.5$ & l \\
\hline Direct floor & $\begin{array}{l}\text { Grey-black mudstone } \\
\text { and fine siltstone }\end{array}$ & 9.0 & l \\
\hline Main floor & Grey quartz sandstone & 2.25 & Calcareous cementation, separation medium, angularity particles \\
\hline \multicolumn{4}{|c|}{ Tab. 2 Gas basic parameters of coal seam } \\
\hline Coal seam & Gas pressure $(\mathrm{MPa})$ & Gas content $\left(\mathrm{m}^{3} / \mathrm{t}\right)$ & $\begin{array}{l}\text { damping factor of gas flow rate } \\
\text { per hole } \alpha\left(\mathrm{d}^{-1}\right)\end{array}$ \\
\hline $3 \#$ & $0.05 \sim 0.11$ & $4.23 \sim 5.10$ & $0.2430 \sim 0.2919$ \\
\hline
\end{tabular}

The E type three-roadway layout is in the mining face. Transportation lane and return airway locate on either side of face. Special gas drainage roadway locates above return airway along the coal seam roof. All together, it is used to return air auxiliary and discharge gas of goaf. The section of three roadways is rectangle. Its support pattern is combined support of bolt-mesh. The roadway layout of mining face shown as in Figure 1.

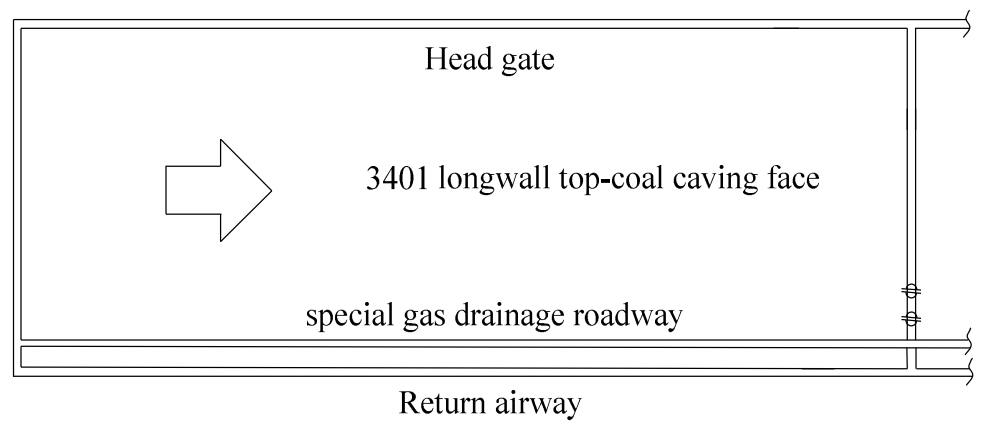

Fig. 1 Roadway layout diagram in 3401 working face

\section{The relationship between strata behaviors and gas emission}

\section{Mining face strata behavior regularity}

In the process of face advancing, periodic strata behaviors of working face shown as changes of support resistance, increase of pilot support pressure, Side fall roof caving of coal wall, change of degree of fragmentation in roof of head face, etc. Above all, the most sensitive changes is the support resistance of hydraulic support, which also can realize the continuous monitoring ${ }^{[3]}$.So using YHY60 mine-used continuous monitoring system. According to the characteristic of the monitoring instruments, layout 20 outstations in 3401 working face, the pressure sensors are installed in corresponding support, which connect to the hydraulic pillar by channel hydraulic pipe.

The range of periodic weighting length in 3401 fully mechanized caving face is form $6.6 \mathrm{~m}$ to $15.6 \mathrm{~m}$, the average of periodic weighting length in top-face is $11.3 \mathrm{~m}$,the middle and lower respectively of periodic weighting length is $11.0 \mathrm{~m}$ and $11.1 \mathrm{~m}$, then the average of periodic 
weighting length in 3401 fully mechanized caving face is $11.1 \mathrm{~m}$.It has a little difference of periodic weighting length among the lop, middle and lower of 3401 working face, and the dynamic load coefficient of periodic weighting in lop ,middle and lower of 3401 working face respectively 1.36 and 1.51 , the average value is1.4.

\section{The effect of Abutment pressure on migration of pressure relief gas}

Layout 6 stress sensors begin from the site 30m away from the coal wall in the roadway and the distance among each sensor is $10 \mathrm{~m}$, the depth of each hole is $8 \mathrm{~m}$, which for the determination of the dynamic variation of abutment pressure. Meanwhile monitoring the gas emission, then obtain the relation curve among the abutment pressure, permeability and the distance away from the working face according to the real data. As shown in Fig.2.

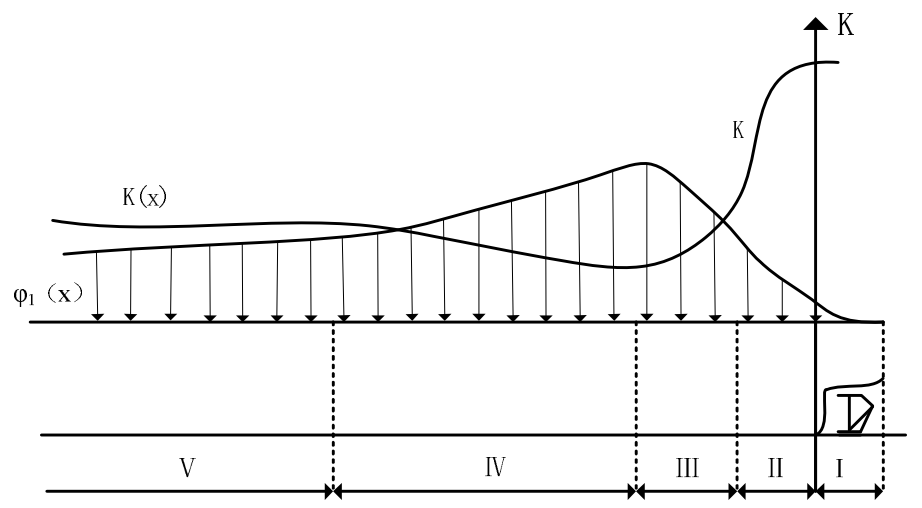

Fig. 2 The variation curve of permeability coefficient in working face

(1) Abutment pressure of top of the fully mechanized support and gob shield tends to 0 , and the top-coal in a loose and discrete state, in which the gas is free diffusion and along with the accumulation of high concentrations gas, as shown the zone I in Fig 2, which is called free diffusion zone of pressure less gas.

(2) Range 0 to $5 \mathrm{~m}$ in front of the coal wall of working face is called stress decreasing zone, as shown the zone II in Fig 2. The abutment pressure of this area decreases constantly, which caused the expansion deformation, the crushing of coal, strength decreases, fracture development and the permeability increases sharply; meanwhile, the gas desorption strengthening and flow increases, formed the effect of flow increases along with the pressure relief. Then gas inrush to the working face from the open migration channel during mining.

(3) Range 5 to $9 \mathrm{~m}$ in front of the coal wall of working face is called stress rapidly increasing zone, as shown the zone III in Fig 2. The increasing of abutment pressure caused the shrinkage and closed of the fracture and pore and the decreasing of the permeability with a large gradient, which changed the normal inrush characteristics of gas, then the gas flow decreased gradually.

(4) Range 25 to $50 \mathrm{~m}$ in front of the face is called stress slowly decreased zone. As shown the zone IV in Fig 2. The abutment pressure decreased gradually after the peaking pressure, caused the shrinkage and closed of the fracture and pore and the gradually decreasing of the permeability gradient, then gas flow tends to decreases because of the changing of the normal inrush characteristics of gas.

(5) Beyond 50m in front of the face is called stress steadiness zone, as shown the zone V in Fig 2. The pressure is normal because of no mining effect in this zone, the variation of permeability and dynamic parameters tends to steady, and then gas emission attenuated normally as the rule of negative exponent.

\section{Relationship between gas emission and periodic weighting of fully mechanized caving face}

Periodic weighting caused the variation of abutment pressure as well as the movement of overlying strata, which effect the gas emission of goaf directly ${ }^{[4]}$. The gas emission characteristics is divided into two stages according to the movement characteristics of overlying strata and variation rule of abutment pressure, that is slowly changing stage and significantly changing stage.

Obtain the relationship of gas emission in different stages of periodic weighting by the analysis 
of data in ground pressure monitoring and gas real-time monitoring during the normal mining, as shown in Fig 3.

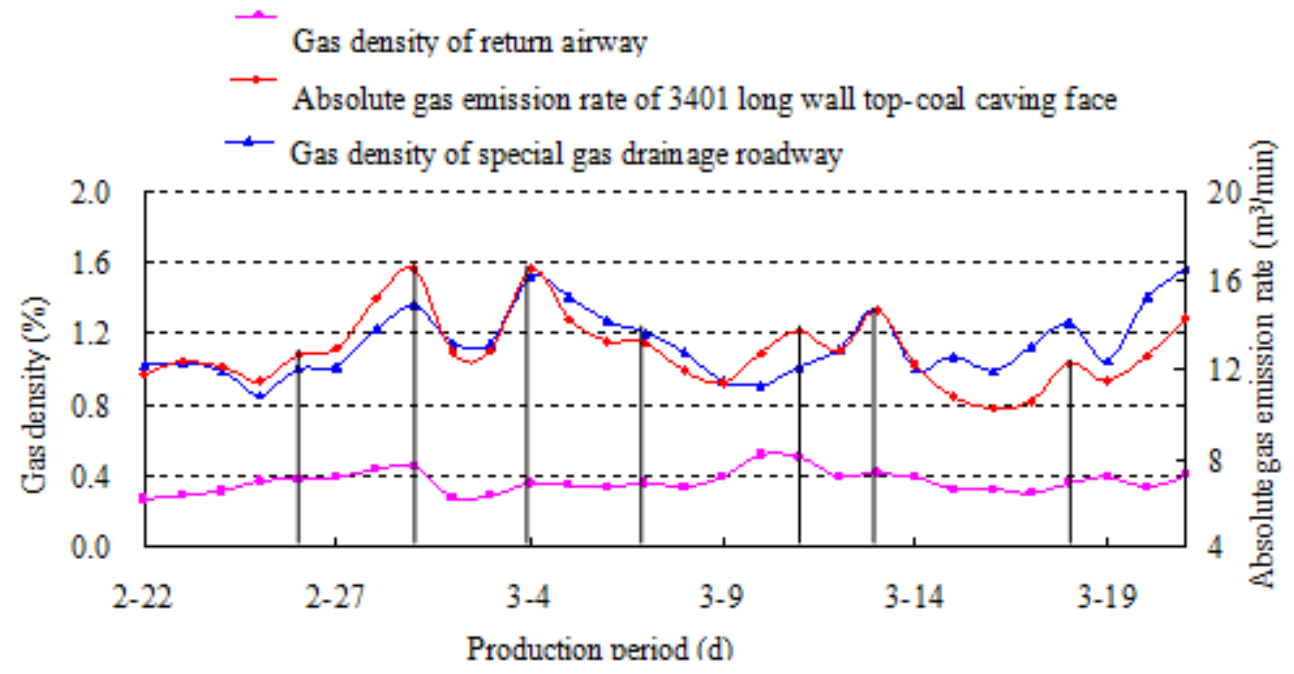

Fig. 3 The variation curve of gas emission with mining time in 3401 working face

As shown in Fig 3, both of absolute and relative gas emission increased suddenly when advanced about $12.9 \mathrm{~m}$ (approximately a periodic weighting length) after the periodic weighting on February 26. Absolute and relative gas emission before periodic weighting respectively is $12.27 \mathrm{~m}^{3} / \mathrm{min}$ and $3.64 \mathrm{~m}^{3} / \mathrm{t}$, and the average respectively is $14.19 \mathrm{~m}^{3} / \mathrm{min}$ and $4.64 \mathrm{~m}^{3} / \mathrm{t}$ after periodic weighting, respectively increased by 16 percent and 28 percent.

Periodic weighting caused the permeability decreasing as well as the permeation volume in front coal body, further result in the increasing of gas pressure. Take advanced distance as a benchmark, the gas emission peak lagging behind the peak pressure about 2.5 to 3 meters (about one day) during normal mining according to the real measurement.

\section{Relationship between coal mining technology and gas emission}

\section{Relation between gas emission and production process}

Production process has a large influence to the gas emission, such as the working state of shearer, coal caving and advancing support etc. In order to research the influence degree of mining process on the gas emission, obtain the distribution curve of gas concentration respectively in the intake and return airflow, 10 meter, 20 meter and 30meter away from the shearer and coal caving point according to the actual situation of working face during normal mining, as shown in Fig 4 and Fig5.

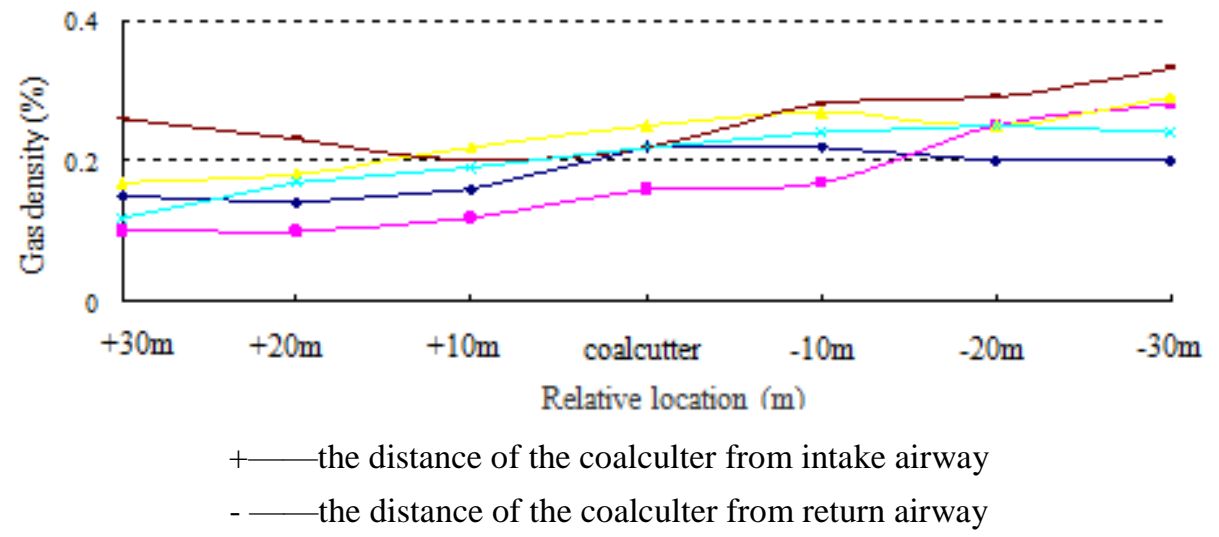

Fig. 4 The distribution curve of gas concentration in the intake and return air side different locations for shearer 


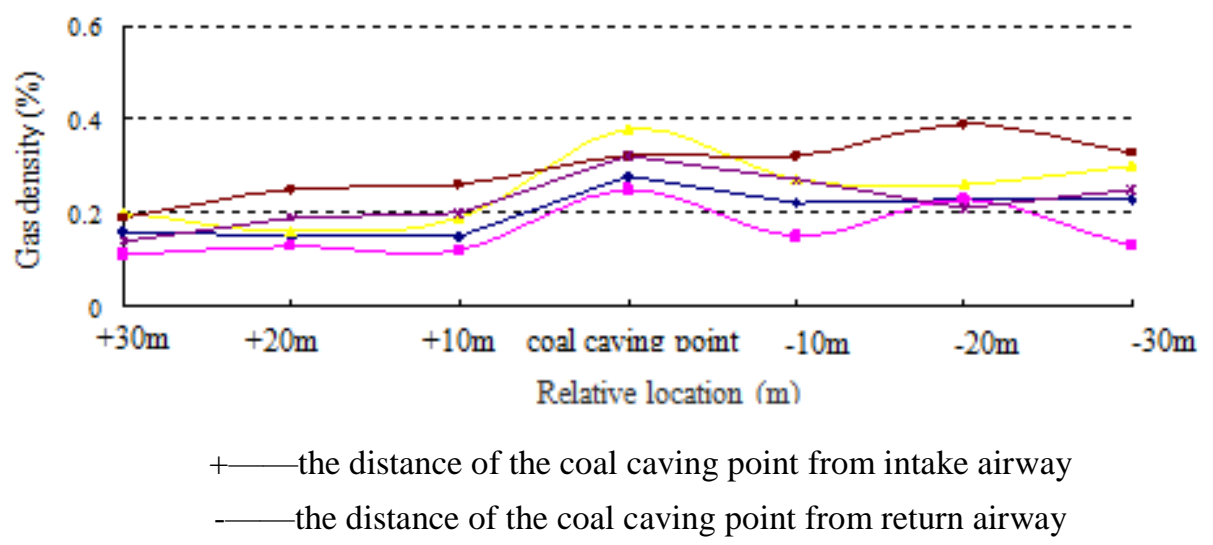

Fig. 5 The distribution curve of gas concentration in the intake and return air side different locations for coal caving point

(1) Gas concentration in intake air changed little and the average gas concentration 20 meters away from the shearer is $13.34 \%$ higher than 30 meters away from the shearer, however, because of the effect of mining process, the average gas concentration in shearer point and point 10 meters away from the shearer is respectively $26.67 \%$ and $41.17 \%$ higher than point 30 meters away from the shearer. The average concentration in intake air is $47.06 \%$ higher than in return air because of mining.

Gas concentration in intake air changed little and the average gas concentration 20 meters away from the coal caving-point is $6.25 \%$ higher than 30 meters away from the coal caving point, however, because of the effect of coal caving process, the average gas concentration in shearer point and point 10 meters away from the shearer is respectively $18.87 \%$ and $44.44 \%$ higher than point 30 meters away from the shearer. The average concentration in intake air is $55.56 \%$ higher than in return air because of coal caving process. So caving coal one-time and largely had a greatest influence to gas emission in fully mechanized caving working face.

\section{Relationship among gas emission, daily output and advance speed}

Related research at home and abroad determining that gas emission is mainly affected by mining production, gas emission is generally considered not proportional to the production of working face [5]. The gas emission has an obvious linear relationship to the daily output and advance speed according to the analysis among gas emission, daily output and advance speed during normal mining in 3401 working face. As shown in Fig 6 and Fig 7.

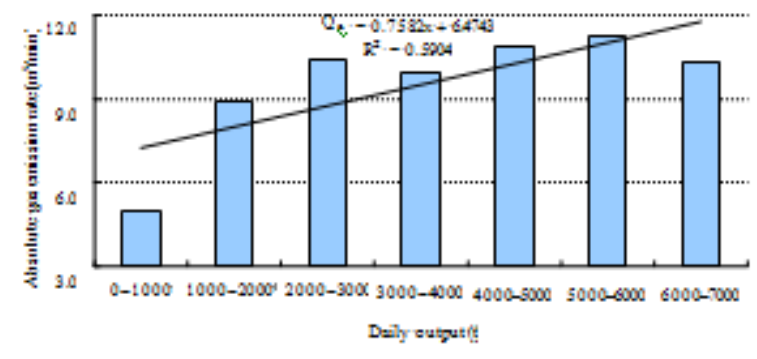

Fig. 6 The relationship between absolute gas emission quantity and daily output

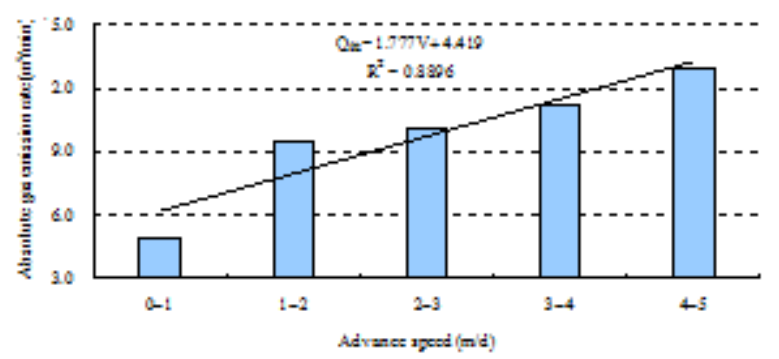

Fig. 7 The relationship between absolute gas emission quantity and advance speed

(1) Analysis shows that when the daily output are 0 to 3000 tons, the absolute gas emission is 4.80 to $12.56 \mathrm{~m}^{3} / \mathrm{min}$, which is approximately linear increase with growth of the daily output and has a large increasing trend because of the greater effect of daily output. When the daily output are 3000 to 6000 tons, the absolute gas emission is 7.26 to $13.36 \mathrm{~m}^{3} / \mathrm{min}$ and with a lower growth trend because of the less influence of daily output.

(2) When the advanced speed is 0 to $2 \mathrm{~m} / \mathrm{d}$, absolute gas emission is 4.80 to $10.45 \mathrm{~m}^{3} / \mathrm{min}$ and linear increase with the growth of advanced speed. It also has a higher growth trend due to the 
greater influence of daily output. Because of the slow advance speed, the completed deformation and fully caving of roof make gas emission from the adjacent seams and surrounding rock with a largely increasing trend. When the advanced speed is 2 to $5 \mathrm{~m} / \mathrm{d}$, absolute gas emission is approximately linear increase with the advanced speed and with a lower growth trend because of the less effect of daily output. The relative gas emission is 2.34 to $6.91 \mathrm{~m}^{3} / \mathrm{t}$ and keeping with a basically stable state.

\section{Conclusions}

(1) The mechanical properties such as gas pressure, porosity and permeability has a greater change because of the abutment pressure in front of working face, which make the gas emission is unbalanced.

(2) During normal mining, peak of gas emission periodically appeared and basically consisted with the periodic weighting length. Peak of gas emission periodically appeared behind the pressure peak about one day.

(3) Though it has more production process in working face and gas in goaf can also be bring into working face, the position and working state of shearer has a greater influence on gas emission.

(4) When the advanced speed is low, absolute gas emission increases linearly with the growth of advanced speed, it also has a higher growth trend due to the greater influence of daily output. When the advanced speed is high, absolute gas emission is approximately linear increase with the advanced speed and with a lower growth trend because of the less effect of daily output.

\section{References}

[1] Qian Miaogao, Xu Jialin. The Discussion of Several Problems Faced in the Development of Coal Industry [J].Journal of Mining \& Safety Engineering, 2006, 23 (2):127-132 (In Chinese)

[2] Fan Weitang. The Status and Development Direction of Thick Coalseam Fully Mechanized Technology in China [J]. Journal of China Coal Society, 1993, 18 (1):5-6 (In Chinese)

[3] Li Shugang, Liu Zhiyun. Study of Ground Pressure and Gas Emission Monitoring of Fully Mechanized Caving Face [J]. Gound Pressure and Strata Control, 2002, 19 (1): 100-103 (In Chinese)

[4] Cui Shujiang. Study of the Relation between Strata Behaviors and Gas Emission [J], Coal, 2010, 19(7):11-12(In Chinese)

[5] Qin Yueping, Wang Jinxue, Xing Junhai. Study of Gas Emission Characteristics of Fully Mechanized Caving Face [J].1997, 25 (8):112-116(In Chinese) 